\title{
Transfer Knowledge Dosen Akuntansi Pada Masa Pandemi
}

\author{
Nur Ravita Hanun ${ }^{1}$, Aisha Hanif ${ }^{2}$, Muhammad Yani ${ }^{3}$ \\ Fakultas Bisnis, Hukum dan Ilmu Sosial Universitas Muhammadiyah Sidoarjo ${ }^{123}$ \\ email korespondensi: hanun@umsida.ac.id
}

\begin{abstract}
Abstrak: Penelitian ini bertujuan untuk menguji secara empiris : 1) Peran IT 2) Pengaruh proses pembelajaran akuntansi 3) Respon Institusi atas Covid-19 terhadap Kinerja Mengajar dosen Akuntansi Dengan Transfer Knowledge Sebagai Variabel Intervening, yang terdiri dari tiga variabel bebas yaitu Peran IT(X1), Proses Pembelajaran Akuntansi (X2), Respon Institusi atas Covid-19 (X3) dengan variabel terikat Kinerja Mengajar Dosen Akuntansi $(Y)$, dan variabel intervening Transfer Knowledge (Z).

Sumber data yang digunakan dalam penelitian ini berasal dari jawaban kuesioner yang di sebarkan kepada Bapak / Ibu Dosen Akuntansi Se-Indonesia. Kuesinoner disebarkan melalui link geogle from, responden yang mengisi berjumlah 124 Orang. Teknik analisis menggunakan data yang meliputi outer model, inner model dan analisis jalur dengan program Smart PLS 3.0.

Hasil penelitian ini adalah proses pembelajaran akuntansi dan respon institusi atas covid19 memiliki pengaruh positif dan signifikan terhadap kinerja mengajar dosen akuntansi dan dimediasi oleh transfer knowledge
\end{abstract}

Kata kunci: Proses Pembelajaran Akuntansi, Respon Institusi, Transfer Knowledge, Kinerja Mengajar

Di era persaingan dan perkembangan globalisasi, pendidikan merupakan hal yang dipertimbangkan dalam dunia kerja. Salah satu wadah penyedia jasa pendidikan yaitu universitas. Dimana universitas sendiri wajib menyediakan tenaga pengajar yang ahli di bidangnya serta fasilitas yang mendukung pembelajaran untuk mempersiapkan mahasiswa menghadapi masa depan yang sesungguhnya. Agar menghasilkan lulusan yang berkualitas, perguruan tinggi harus terus meningkatkan kualitas pada sistem pendidikannya. Pendidikan akuntansi ditujukan untuk mendidik mahasiswa akuntansi agar bekerja sebagai seorang akuntan professional yang memiliki pengetahuan dan berkompeten di bidangnya.

Akuntansi merupakan suatu ilmu yang sangat penting dan dibutuhkan yang tidak akan pernah lepas dari kehidupan. Transfer keilmuan dari seorang dosen tentang akuntansi menjadi sangat penting. Melalui pemahaman pada mata kuliah akuntansi dapat diketahui seberapa cukupkah ilmu akuntansi yang telah dimiliki oleh seorang akuntan agar bisa melaksanakan peran profesi akuntan di dunia bisnis yang sesuai etika dan moral. Pemahaman tentang akuntansi dinyatakan dengan seberapa mengerti seorang mahasiswa terhadap apa yang sudah dipelajari. Bisa dilihat tanda bahwa seorang mahasiswa memahami mata kuliah akuntansi tidak cukup ditunjukkan dari nilai yang didapatkannya tetapi juga apabila mahasiswa mengerti dan dapat menguasai ilmu pengetahuan dan konsep-konsepnya.

Pendidikan merupakan aspek yang sangat penting bahkan dikatakan determinan dalam pembentukan karakter dan internalisasi nilainilai demokrasi.Kegagalan demokrasi Indonesia selama ini disinyalir salah 
satunya disebabkan oleh disorientasi pendidikan dan paradigma yang salah dalam proses pendidikan. Dapat dikatakan bahwa pendidikan yang berlangsung selama ini hanya diartikan sebagai transfer dalam pembelajaran atau diajarkan dan kurang dipraktekkan dalam realitas sosial. Perguruan tinggi adalah pilar utama yang berfungsi sebagai penyanggah sumber daya manusia (SDM) yang berkualitas. Unsur penting dalam menggerakkan roda dari suatu perguruan tinggi adalah dosen.Kinerja dosen dari suatu perguruan tinggi dapat diuraikan dan diwujudkan ke arah peningkatan kinerja dosen yang mendukung pengembangan tujuan pendidikan nasional yang tercantum dalam Undang Undang Sisdiknas No. 20 Tahun 2003.

Daryanto (2007) mengemukakan bahwa proses transfer knowledge yang ada di Indonesia masih belum tumbuh dan berkembang dengan baik. Menurut Irawati (2006) permasalahan transfer knowledge di Indonesia dikarenakan PT hanya menitikberatkan pada aktivitas pembelajaran dibanding aktivitas riset, beberapa perguruantinggi tidak memiliki tujuan atau prioritas riset, dan pendanaan riset masih minim. Riset yang tidak terarah dan terkesan tumpang tindih dapat dilihat dari minimnya publikasi ilmiah, hasil riset yang tidak dapat dimanfaatkan karena tidak sesuai dengan kebutuhan pengguna. Knowledge transfer adalah sebuah proses atau cara dimana para peneliti melakukan penyebaran pembuktian suatu teori atau menyebarkan pengetahuan baru (Profetto, 2004). Menurut Profetto (2004), knowledge transfer adalah pertukaran,sintesis dan aplikasi etika dari pengetahuan dalam suatu sistem hubungan yang kompleks antara peneliti dan pengguna.

\section{METODE}

Berdasarkan permasalahan yang diteliti, pendekatan yang digunakan untuk penelitian ini adalah pendekatan kuantitatif yang memusatkan pada pada pengujian hipotesis. Hermawan \& Amirullah (2016) menjelaskan bahwa penelitian kuantitaif adalah data penelitian yang dikumpulkan dengan instrument yang valid dan reliabel kemudian dilakukan pengolahan data dan analisis data penelitian dengan menggunakan alat-alat uji statisik yang relevan dengan tujuan penelitian.

Alasan peneliti menggunakan metode kuantitatif yaitu karena tujuan dari penelitian ini sendiri untuk membuktikan pengaruh dari proses pembelajaran akuntansi dan respon institusi atas covid-19 terhadap kinerja mengajar dosen akuntansi yang di mediasi oleh transfer knowledge.

Dalam melakukan suatu penelitian dibutuhkan perencanaan dan perancangan agar penelitian dapat berjalan dengan baik, lancar, efektif, dan sistematis. Rerangka penelitian merupakan rencana secara menyeluruh dari penelitian yang akan dilakukan oleh peneliti, mulai dari perumusan masalah pengujian sampai pada analisis data yang selanjutnya disimpulkan dan diberi saran..

\section{HASIL}




\section{A. Evaluasi Measurement (Outer Model)}

1. Convergent Validity

Convergent validity digunakan untuk mengukur kesesuaian antar hasil indikator pengukuran variable dengan konsep teoritis yang menjelaskan keberadaan indikator tersebut. Hasil dari analisis terdapat satu indikator yang memiliki nilai loading factor dibawah 0.70 atau tidak valid yaitu PIT1, Oleh karena tidak memenuhi kriteria convergent validity maka indikator PIT1 dikeluarkan dari model.

\section{Tabel 1. Convergent Validity (AVE)}

\begin{tabular}{lcc}
\hline & $\begin{array}{c}\text { Average Variance } \\
\text { Extracted (AVE) }\end{array}$ & Keterangan \\
\hline Kinerja Mengajar Dosen AK & 0,712 & Valid \\
\hline Peran IT & 0,875 & Valid \\
\hline Proses Pembelajaran & 0,683 & Valid \\
\hline Respon Instusi & 0,829 & Valid \\
\hline Transfer Knowladge & 0,645 & Valid \\
\hline
\end{tabular}

Sumber: Output pengolahan dengan Smart PLS 3.0.

Hasil output AVE dari Smart PLS pada tabel 1 yang dihasilkan oleh semua konstruk memiliki nilai $>0.50$, sehingga masing - masing kostruk telah memenuhi persyaratan.

2. Discriminant Validity

Tingkat validitas konstruk dapat diukur dengan cara yang kedua yaitu menggunakan diskriminan validity, disajikan dalam tabel 2 berikut:

Tabel 2. Hasil Uji Discriminant Validity (Fornell-Larcker Criterion)

\begin{tabular}{lccccc}
\hline & $\begin{array}{c}\text { Kinerja } \\
\text { Mengajar } \\
\text { Dosen }\end{array}$ & $\begin{array}{c}\text { Peran } \\
\text { IT }\end{array}$ & $\begin{array}{c}\text { Proses } \\
\text { Pembelajaran }\end{array}$ & $\begin{array}{c}\text { Respon } \\
\text { Instusi }\end{array}$ & $\begin{array}{c}\text { Transfer } \\
\text { Knowladge }\end{array}$ \\
\hline $\begin{array}{l}\text { Kinerja Mengajar } \\
\text { Dosen }\end{array}$ & $\mathbf{0 , 8 4 4}$ & & & & \\
\hline Peran IT & 0,649 & $\mathbf{0 , 9 3 6}$ & & & \\
\hline $\begin{array}{l}\text { Proses } \\
\text { Pembelajaran }\end{array}$ & 0,769 & 0,579 & $\mathbf{0 , 8 2 6}$ & & \\
\hline Respon Instusi & 0,588 & 0,405 & 0,498 & $\mathbf{0 , 9 1 1}$ & \\
\hline $\begin{array}{l}\text { Transfer } \\
\text { Knowladge }\end{array}$ & 0,751 & 0,533 & 0,719 & 0,674 & $\mathbf{0 , 8 0 3}$ \\
\hline
\end{tabular}

Sumber: Output pengolahan dengan Smart PLS 3.0.

Dari tabel 2 dapat dilihat bahwa nilai diagonal yang di cetak tebal adalah akar kuadrat AVE dan nilai dibawahnya adalah korelasi antar konstruk. Nilai akar kuadrat AVE lebih besar daripada korelasi antar 
konstruk, dapat disimpulkan bahwa masing-masing konstruk memiliki diskriminant validity yang baik.

\section{B. Evaluasi Model Struktural (Inner Model)}

Estimasi telah memnuhi kriteria Outer Model, langkah berikutnya melakukan uji model structural (Inner model). Menurut (Ghozali, 2011) tujuan evaluasi model structural (Inner model) untuk memprediksi hubungan antar variabel laten. Dalam menilai inner model dengan SmartPLS dilihat dari nilai $R$-Square $\left(R^{\wedge} 2\right)$ untuk setiap variabel laten endogen. Koefisien determinasi R-square $\left(R^{\wedge} 2\right)$ menunjukkan seberapa besar variabel exsogen menjelaskan variabel endogennya. Nilai R-Square $\left(R^{\wedge} 2\right)$ adalah nol sampai dengan satu.

1. Uji R-Square $\left(R^{\wedge} 2\right)$

Tabel 3. Uji R-Square

\begin{tabular}{lcc}
\hline & R Square & R Square Adjusted \\
\hline Kinerja Mengajar Dosen & 0,718 & 0,709 \\
\hline Transfer Knowladge & 0,657 & 0,648
\end{tabular}

Sumber: Output pengolahan dengan Smart PLS 3.0.

Dari tabel diatas dapat dilihat nilai $\mathrm{R}$ Square untuk variabel Kinerja Mengajar Dosen sebesar 0.718 yang berarti bahwa termasuk kategori kuat. Selanjutnya pada variabel Transfer Knowladge sebesar 0.657 yang berarti bahwa termasuk dalam kategori cukup kuat atau moderat.

2. Path Koefisien

\begin{tabular}{lccccc}
\hline & $\begin{array}{c}\text { Original } \\
\text { Sample }\end{array}$ & $\begin{array}{c}\text { Sample } \\
\text { Mean }\end{array}$ & $\begin{array}{c}\text { Standard } \\
\text { Deviation }\end{array}$ & T Statistics & P Values \\
\hline $\begin{array}{l}\text { Peran IT -> Kinerja } \\
\text { Mengajar Dosen }\end{array}$ & 0,236 & 0,219 & 0,070 & 3,401 & 0,001 \\
\hline $\begin{array}{l}\text { Peran IT -> Transfer } \\
\text { Knowladge }\end{array}$ & 0,105 & 0,105 & 0,087 & 1,206 & 0,228 \\
\hline $\begin{array}{l}\text { Proses Pembelajaran -> } \\
\text { Kinerja Mengajar Dosen }\end{array}$ & 0,375 & 0,359 & 0,092 & 4,083 & 0,000 \\
\hline $\begin{array}{l}\text { Proses Pembelajaran -> } \\
\text { Transfer Knowladge }\end{array}$ & 0,458 & 0,456 & 0,084 & 5,425 & 0,000 \\
\hline $\begin{array}{l}\text { Respon Instusi -> Kinerja } \\
\text { Mengajar Dosen }\end{array}$ & 0,121 & 0,124 & 0,093 & 1,306 & 0,192 \\
\hline $\begin{array}{l}\text { Respon Instusi -> Transfer } \\
\text { Knowladge }\end{array}$ & 0,404 & 0,407 & 0,059 & 6,830 & 0,000 \\
\hline $\begin{array}{l}\text { Transfer Knowladge -> } \\
\text { Kinerja Mengajar Dosen }\end{array}$ & 0,274 & 0,282 & 0,092 & 2,959 & 0,003 \\
\hline
\end{tabular}

Sumber: Output pengolahan dengan Smart PLS 3.0. 


\section{Pengujian Hipotesis}

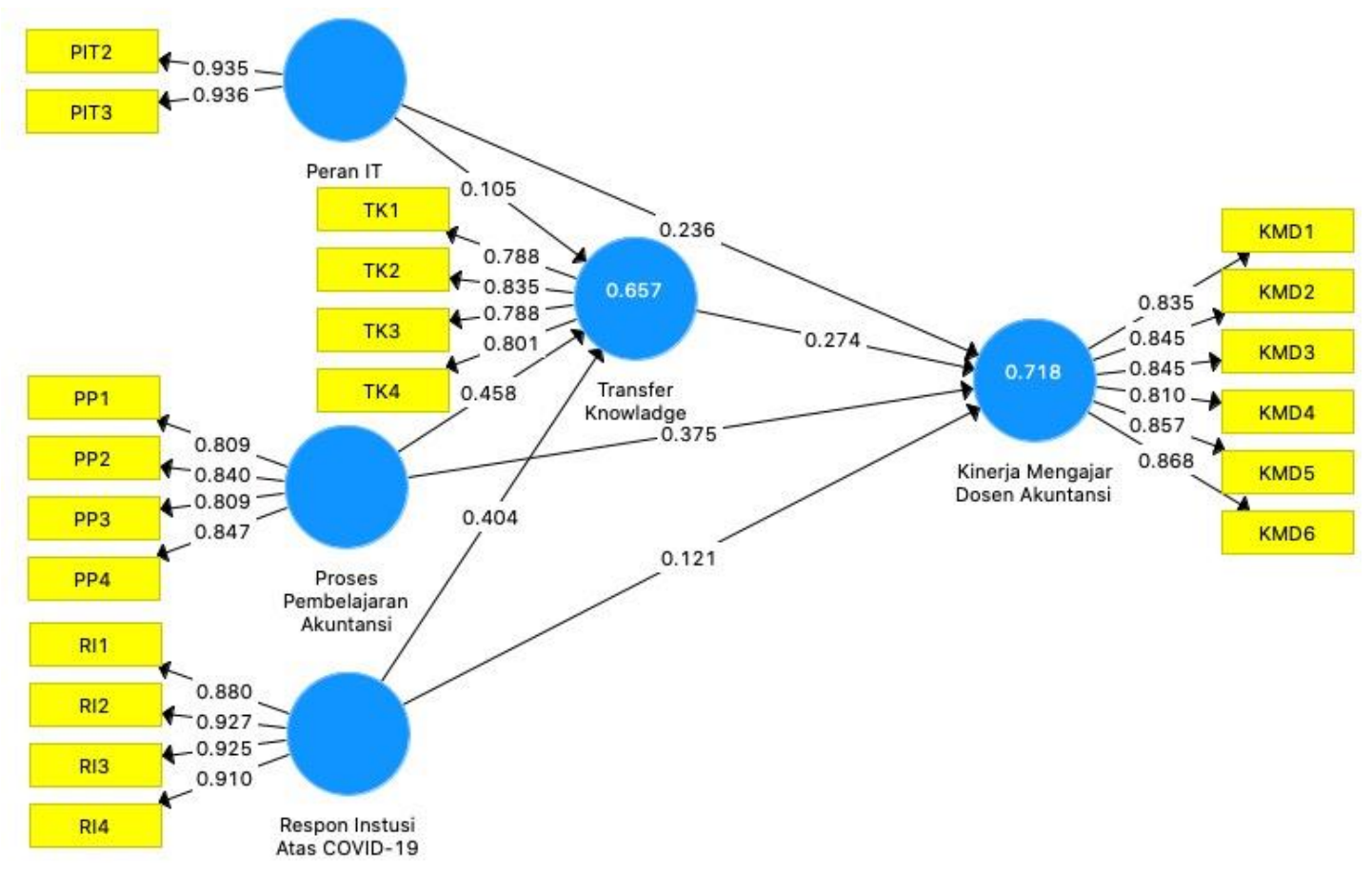

Gambar 1 Pengujian Hipotesis

Sumber: Output pengolahan dengan Smart PLS 3.0.

Pengujian ini dilakukan dengan cara menguji secara langsung (direct effect) terlebih dahulu yaitu pengaruh peran teknologi informasi terhadap kinerja mengajar dosen. Hasil pengujian menunjukkan nilai $t$ sebesar 3.401 pada taraf signifikansi 95\%. Nilai tersebut lebih besar dari t tabel (1.960) dengan $P$ value 0.001 . Hal ini menunjukkan bahwa peran teknologi informasi berpengaruh terhadap kinerja mengajar dosen. Pengujian selanjutnya adalah melihat pengaruh peran teknologi informasi terhadap transfer knowledge. Hasil pengujian menunjukkan nilai t sebesar 1.206 pada taraf signifikansi 95\%. Nilai tersebut lebih kecil dari t tabel (1.960) dengan $P$ value 0.228 . Hal ini menunjukkan bahwa variabel peran teknologi informasi tidak berpengaruh signifikan terhadap kinerja mengajar dosen. Pengujian selanjutnya adalah melihat pengaruh proses pembelajaran terhadap kinerja mengajar dosen. Hasil pengujian menunjukkan nilai t sebesar 4.083 pada taraf signifikansi $95 \%$. Nilai tersebut lebih besar dari t tabel (1.960) dengan $P$ value 0.000 . Hal ini menunjukkan bahwa variabel proses pembelajaran berpengaruh terhadap kinerja mengajar dosen. Selanjutnya adalah menguji pengaruh proses pembelajaran terhadap transfer knowledge. Hasil pengujian menunjukkan nilai t sebesar 5.425 pada taraf signifikansi $95 \%$. Nilai tersebut lebih besar dari t tabel (1.960) dengan $P$ value 0.000 . Hal ini menunjukkan bahwa variabel proses pembelajaran berpengaruh terhadap transfer knowledge. Pengujian selanjutnya adalah melihat pengaruh respon institusi terhadap kinerja mengajar dosen. Hasil pengujian menunjukkan nilai $t$ sebesar 
1.306 pada taraf signifikansi 95\%. Nilai tersebut lebih kecil dari t tabel (1.960) dengan $P$ value 0.192. Hal ini menunjukkan bahwa variable respon institusi tidak berpengaruh signifikan terhadap kinerja mengajar dosen. Selanjutnya adalah menguji pengaruh respon institusi terhadap transfer knowledge. Hasil pengujian menunjukkan nilai t sebesar 6.830 pada taraf signifikansi 95\%. Nilai tersebut lebih besar dari t tabel (1.960) dengan $P$ value 0.000 . Hal ini menunjukkan bahwa variable respon institusi berpengaruh terhadap transfer knowledge. Pengujian selanjutnya adalah melihat pengaruh transfer knowledge terhadap kinerja mengajar dosen. Hasil pengujian menunjukkan nilai t sebesar 2.959 pada taraf signifikansi $95 \%$. Nilai tersebut lebih besar dari t tabel (1.960) dengan $P$ value 0.003 . Hal ini menunjukkan bahwa variable transfer knowledge berpengaruh terhadap kinerja mengajar dosen. Pengujian indirect effect yang pertama menunjukkan bahwa variable transfer knowledge mampu memediasi pengaruh proses pembelajaran terhadap kinerja mengajar dosen dengan nilai t sebesar 2.647 dan $P$ value 0.008 . Pengujian indirect effect selanjutnya menunjukkan bahwa variable transfer knowledge mampu memediasi pengaruh respon institusi terhadap kinerja mengajar dosen dengan nilai $t$ sebesar 2.618 dan $P$ value 0.009 . Sedangkan pengujian selanjutnya menunjukkan bahwa variable transfer knowledge tidak mampu memediasi pengaruh peran teknologi informasi terhadap kinerja mengajar dosen dengan nilai t sebesar 0.987 dan $P$ value 0.324 .

Hasil uji hipotesis 1 menunjukkan bahwa variabel peran teknologi informasi berpengaruh terhadap kinerja mengajar dosen. Saat ini teknologi informasi memiliki peran yang penting yaitu sebagai media dalam menyampaikan dan memperoleh informasi dari bebagai sumber dan dapat dilakukan secara real time (Rahadi, 2007). Terutama pada era digital seperti saat ini, pemanfaatan teknologi informasi jamak dilakukan dalam berbagai lini kehidupan, salah satunya adalah dalam dunia pendidikan. Pemanfaatan serta pengembangan teknologi informasi pada dunia pendidikan telah menjadi hal yang umum dan mudah ditemui dalam kegiatan belajar mengajar saat ini (Zepiliana et al., 2012). Peran teknologi informasi dalam dunia pendidikan khususnya perguruan tinggi adalah sebagai media dalam proses pengajaran, baik dalam mengakses bahan ajar hingga memberikan tugas kepada mahasiswa. Hal ini tentunya akan meningkatan kompetensi dosen yang meliputi kompetensi pedagogic, kompetensi kepribadian, kompetensi social dan kompetensi professional. Nantinya kompetensi dosen akan menentukan aspek kinerja dari dosen itu sendiri (Zepiliana et al., 2012).

Hasil uji hipotesis 2 menunjukkan bahwa variabel peran teknologi informasi tidak berpengaruh signifikan terhadap transfer knowledge. Pada dasarnya knowledge dibagi menjadi dua, yaitu tacit knowledge dan explicit knowledge. Tacit knowledge berada dalam pikiran manusia dalam bentuk intuisi, judgement, skill, values dan belief. Sedangkan explicit knowledge adalah bentuk pengetahuan yang sudah ditransfer dalam bentuk dokumen dan lebih mudah dalam didistribusikan dengan menggunakan berbagai 
media (Antoro, 2014). Peran manusia dalam proses transfer knowledge adalah tidak hanya sebagai sumber pengetahuan tetapi juga sebagai pemeran utama dari proses transfer pengetahuan itu sendiri. Sehingga jika sebuah proses transfer pengetahuan tidak dapat berjalan dengan baik maka yang menjadi masalah utama terletak pada ketidakmauan dan ketidakmampuan manusia menjalankan proses transfer knowledge. Proses transfer knowledge tersebut dapat berjalan, selama manusia memang terdorong untuk melakukannya walaupun tanpa bantuan teknologi (Antoro, 2014). Sehingga dapat disimpulkan bahwa teknologi informasi tidak memiliki pengaruh yang signifikan terhadap proses transfer knowledge.

Hasil uji hipotesis 3 menunjukkan bahwa variable proses pembelajaran berpengaruh terhadap kinerja mengajar dosen. Proses pembelajaran meliputi perencanaan pembelajaran, pelaksanaan pembelajaran, dan evaluasi hasil belajar (Dimyati \& Mudjiono, 2006). Selama pandemic covid 19 terjadi, proses pembelajaran yang terjadi pada semua jenjang pendidikan adalah dengan menerapkan pembelajaran jarak jauh (PJJ) menggunakan bantuan teknologi informasi. Proses pembelajaran yang baik dan berjalan efisien dapat menghasilkan manfaat yang dirasakan oleh dosen, mahasiswa, dan juga bagi perguruan tinggi (Sahyar, 2009).

Hasil uji hipotesis 4 menunjukkan bahwa variable proses pembelajaran berpengaruh terhadap transfer knowledge. Kegiatan perencanaan pembelajaran, pelaksanaan pembelajaran, dan evaluasi hasil belajar yang dilakukan oleh dosen dalam menjalankan proses pembelajaran yang baik sangat menentukan efektifitas dari proses transfer knowledge kepada mahasiswa. Transfer knowledge adalah dasar dari proses pembelajaran dan transfer pengetahuan guna menciptakan lebih banyak peluang dan ruang untuk belajar. Tidak ada inovasi tanpa belajar dan tanpa inovasi, maka mahasiswa tidak akan bisa tumbuh (Antoro, 2014).

Hasil uji hipotesis 5 menunjukkan bahwa variabel respon institusi tidak berpengaruh signifikan terhadap kinerja mengajar dosen. Hasil penelitian ini sejalan dengan hasil penelitian yang dilakukan Antoro (2014) dimana respon institusi selama pandemic covid 19 terjadi, tidak mempengaruhi kinerja mengajar dosen akuntansi dalam proses pembelajaran yang menerapkan pembelajaran jarak jauh (PJJ).

Hasil uji hipotesis 6 menunjukkan bahwa variabel respon institusi berpengaruh signifikan terhadap transfer knowledge. Hasil penelitian ini membuktikan bahwa komitmen manajemen puncak terbukti berpengaruh signifikan positif terhadap transfer knowledge. Hasil penelitian ini sejalan dengan penelitian dari Windarti \& Sukmawati (2011) yang juga menunjukkan bahwa kebijakan top manajemen menentukan pengembangan karyawan dalam skill, habit,attitude melalui kegiatan transfer knowledge. 
Hasil uji hipotesis 7 menunjukkan bahwa variable transfer knowledge berpengaruh signifikan terhadap kinerja mengajar dosen. Nonaka \& Takeuchi (1995) Nonaka dan Takeuchi (1995) membagi knowledge menjadi dua, yaitu tacit knowledge dan explicit knowledge. Tacit knowledge merupakan knowledge yang statis di dalam benak manusia berupa intuisi, judgment, skill, nilai, dan keyakinan yang sangat sulit diformulasikan dan dibagikan kepada orang lain. Sedangkan explicit knowledge adalah knowledge yang sudah terkodifikasi dalam bentuk dokumen sehingga dapat dengan mudah didistribusikan dengan menggunakan berbagai media. Kedua jenis knowledge tersebut dapat dikonversi melalui empat jenis konversi, yaitu sosialisasi, eksternalisasi, kombinasi, dan internalisasi. Proses distribusi pengetahuan yang baik dari dosen kepada mahasiswa dapat meningkatkan efektifiktas dari kinerja mengajar dosen yang meliputi kompetensi pedagogic, kompetensi professional, kompetensi social, dan kompetensi kepribadian.

\section{KESIMPULAN}

Hasil penelitian ini menunjukkan bahwa variable peran teknologi informasi, variable proses pembelajaran, dan variable transfer knowledge berpengaruh signifikan terhadap kinerja mengajar dosen. Hal ini menandakan bahwa penggunaan teknologi informasi yang tepat dan baik, kegiatan pembelajaran dan proses distribusi pengetahuan yang tepat sasaran kepada mahasiswa akan meningkatkan efektifitas dari kinerja mengajar dosen. Sedangkan untuk variable respon institusi tidak berpengaruh signifikan terhadap kinerja mengajar dosen. Hasil penelitian selanjutnya menunjukkan bahwa variable proses pembelajaran dan variable respon institusi berpengaruh signifikan terhadap transfer knowledge. Kegiatan perencanaan pembelajaran, pelaksanaan pembelajaran, dan evaluasi hasil belajar yang dilakukan oleh dosen serta respon institusi yang baik sangat menentukan efektifitas dari proses transfer knowledge kepada mahasiswa, karena transfer knowledge merupakan dasar dari proses pembelajaran dan transfer pengetahuan guna menciptakan lebih banyak peluang dan ruang untuk belajar. Sehingga jika tidak ada inovasi maka tidak ada proses belajar dan tanpa inovasi maka mahasiswa tidak akan bisa tumbuh.

\section{DAFTAR PUSTAKA}

Antoro, D. (2014). Pengaruh Kepemimpinan, Budaya Organisasi, dan Komitmen Manajemen Puncak terhadap Transfer Knowledge dan Dampaknya terhadap Kinerja Dosen. Jurnal Bisnis Dan Ekonomi, 21(2).

Daryanto, A. (2007). Kebijakan Riset Industri Di Indonesia: Stagnasi, Tantangan dan Peluang, National Conference Research and

Technology Policy in Indonesia: Challenge, Stagnancy and Opportunity. UNPAR, Bandung.

Dimyati, \& Mudjiono. (2006). Belajar dan Pembelajaran. Cetakan Ketiga. 
Jakarta : PT. Rineka Cipta.

Hermawan, S., \& Amirullah. (2016). Metode Penelitian Bisnis Pendekatan Kuantitatif \& Kualitatif. Media Nusa Creative.

Irawati, D. (2006). Understanding The Triple Helix Model from The Perspective of the Developing Country: A Demand or A Challange for Indonesian Case Study?

Nonaka, I., \& Takeuchi, H. (1995). The knowledge-creating company: How Japanese companies create the dynamics of innovation. Oxford university press.

Profetto, J. (2004). Knowledge transfer: what it is and what it takes to do it best. Water Cooler Presentation.

Rahadi, D. R. (2007). Peranan teknologi informasi dalam peningkatan pelayanan di sektor publik. Seminar Nasional Teknologi, 2007, 1-13.

Sahyar, S. (2009). Pengaruh Kompetensi Dosen dan Proses Pembelajaran Terhadap Keunggulan Bersaing Program Studi di Pendidikan Tinggi. Ekuitas (Jurnal Ekonomi Dan Keuangan), 13(3), 308-325.

Windarti, W., \& Sukmawati, A. (2011). Faktor-Faktor Kunci Kesuksesan Implementasi Manajemen Pengetahuan pada PT Unilever Indonesia Tbk. Jurnal Manajemen Dan Organisasi, 2(1), 13-26.

Zepiliana, W. E., Sufian, S., \& Widiyanto, I. (2012). Analisis Pengaruh Pemanfaatan Teknologi Informasi, Budaya Akademik Dan Kompetensi Dosen Terhadap Kinerja Jurusan/Program Studi Di Universitas Diponegoro. Diponegoro University. 